\section{Demiryolu Mühendisliği}

Temmuz 2021

Say1:14, Sayfa: 217-233

Araştırma Makalesi
Railway Engineering

July 2021

Issue:14, Page: 217-233

Research Article

doi: 10.47072/demiryolu.937508

http://dergipark.org.tr/demiryolu

e-ISSN: 2687-2463, ISSN: 2149-1607

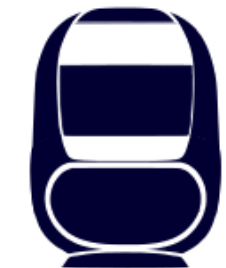

\title{
Design of the Active Control Algorithm to Reduction of the Vibrations due to Interaction High-Speed Railway Vehicle Bogie and Structure
}

\author{
Mehmet Akif KOÇ ${ }^{* 1}$ (D), Mustafa EROĞLU ${ }^{2}$ (D) İsmail ESEN ${ }^{3}$ (D) \\ ${ }^{1}$ Sakarya Applied Sciences University, Technology Faculty/Mechatronics Engineering, Sakarya, Turkey \\ ${ }^{2}$ Sakarya University, Emgineering Faculty/Mechanical Engineering, Sakarya, Turkey \\ ${ }^{3}$ Karabük University, Emgineering Faculty/Mechanical Engineering, Karabük, Turkey \\ *makoc@edu.tr
}

(Alınış/Received: 15.05.2021, Kabul/Accepted: 27.06.2021, Yayımlama/Published: 31.07.2021)

\begin{abstract}
This study analyzes excessive vibrations that occurred on the railway vehicle bogie with the computer simulation of a 4-DOF half car railway bogie dynamic physical model and Euler-Bernoulli flexible bridge beam with the simply supported boundary conditions has been introduced considering some limitations which affect problem formulation. To reduce these excessive vibrations other than conventional suspension systems such as passive one, an active suspension system has been designed and attached to the primary suspension system of the railway bogie car. Then, to control these active suspension systems, a control algorithm based on PID and SMC is considered. The coupled equation of motion of the railway bogie car and flexible Euler-Bernoulli bridge beam is obtained by Hamilton's principle in the time domain with the active suspension system. Finally, to demonstrate the effect of the active suspension system with the PID and SMC algorithm upon these excessive vibrations, a computer simulation has been implemented, and the results are presented comparatively. Consequently, the maximum railway vehicle bogie vertical displacement and vertical acceleration have been significantly reduced.
\end{abstract}

Keywords: Railway vehicle bogie, Active control, Active suspension, PID algorithm, SMC algorithm

\section{Yüksek Hızlı Demiryolu Araç Bojisi ve Yapı Etkileşiminden Kaynakı Titreşimlerin Azaltılmasıı İçin Aktif Kontrol Algoritması Tasarımı}

Öz: Bu çalışma 4-DOF yarım araç dinamik fiziksel modeli kullanarak oluşturulmuş demiryolu aracı ve basit mesnetli sınır şartlarına sahip Euler-Bernoulli kirişinde meydana gelen aşırı titreşimleri problem formülasyonunu etkileyen bazı sınırlamalar dikkate alarak incelemektedir. Pasif süspansiyon sistemleri gibi geleneksel süspansiyon sistemleri dışında, bu aşırı titreşimleri azaltmak için, demiryolu boji vagonunun birincil süspansiyon sistemine aktif bir süspansiyon sistemi tasarlanmış ve eklenmiştir. Daha sonra bu aktif süspansiyon sistemlerini kontrol etmek için PID ve SMC tabanlı bir kontrol algoritması düşünülmüştür. Demiryolu boji vagonu ve esnek Euler-Bernoulli köprü kirişinin birleşik hareket denklemi, aktif süspansiyon sistemi ile zaman alanında Hamilton prensibi ile elde edilmiştir. Son olarak, PID ve SMC algoritması ile aktif süspansiyon sisteminin bu aşırı titreşimler üzerindeki etkisini göstermek için bir bilgisayar simülasyonu uygulanmış ve sonuçlar karşılaştırmalı olarak sunulmuştur. Sonuç olarak, maksimum demiryolu aracı boji düşey yer değiştirmesi ve düşey ivme önemli ölçüde azaltılmıştır.

Anahtar kelimeler: Demiryolu araç bojisi, Aktif kontrol, Aktif süspansiyon, PID algoritması, SMC algoritmas1

\section{Introduction}

Highways are mostly preferred in today's vehicles. However, transportation on highways cannot be safer and more economical than railways. With the developments in railways, rail vehicles are preferred due to faster and more comfortable transportation. In the last century, high-speed trains have attracted considerable attention to transport people or cargo from one place to another. The first high-speed train in the world was Tokaido Shinkansen, which operated on the line between

Cite as: M. A. Koç, M. Eroğlu, İ. Esen, "Design of the active control algorithm to reduction of the vibrations due to interaction high-speed railway vehicle bogie and structure," Railway Engineering, no. 14, pp. 217-233, July. 2021, doi: 10.47072/demiryolu.937508 
Tokyo and Osaka in Japan in 1964, and its speed was $200 \mathrm{~km} / \mathrm{h}$. In addition, this speed gradually increased to 250-300 km/h and in 1996 to $443 \mathrm{~km} / \mathrm{h}$. In 2007, the Paris-Lyon high-speed train in France reached $574.8 \mathrm{~km} / \mathrm{h} \mathrm{[1]}$. The highest speed in history is the maglev trains that use magnetic levitation technology in Japan and can reach $603 \mathrm{~km} / \mathrm{h}$ [2]. However, with the increase of the speed of high-speed trains, some problems arise regarding the driving safety of the railway vehicle and the comfort of the transported passengers. One of these problems arises from the dynamic interaction between the train and the flexible structure that the high-speed train passes over. In addition, there are studies such as wind load [3] [4], track irregularity [5], collision load [6], earthquake [7] [8] in the interaction problems of high-speed trains.

The moving load passing over flexible structures such as bridges at a certain speed interacts with the bridge, vibrates the bridge, and affects the moving load passing over the vibrating bridge. When the literature is examined, those flexible structures such as bridges can be modeled as beams. In literatures on this subject, bridges have been modeled using Euler-Bernoulli [9], Timoshenko [10], and Shear beam theorems. In order to reduce the effects mentioned earlier on vehicle cabins and overcome the problems mentioned above for high-speed trains, the design of suspension systems is substantial. In passive suspension systems, the coefficients of spring and dashpot elements are fixed and cannot be changed. It is difficult to increase the passenger comfort and driving safety of high-speed trains or heavy vehicles with passive suspension systems. For this reason, semi-active suspension systems have been developed due to changing the dashpot parameter in passive suspension systems. In semi-active suspension systems, dashpot is designed using a fluid that can respond to the magnetic field. In addition to these, an active suspension system can maximize the driving safety and passenger comfort of the vehicles. Active suspension systems are actually formed by the addition of actuators that can apply force in the vertical direction in addition to the spring and dashpot.

It is seen that active suspension controls are used to increase the driving safety and passenger comfort of high-speed trains or heavy vehicles. Specific controllers are preferred in order to increase the performance of the active suspension. When the literature is examined, many researchers have chosen the PID (Proportional-Integral-Derivative) controller for its design convenience and superior performance to provide active vibration control of high-speed trains or heavy vehicles. Güçlü carried out the active control of passenger and vehicle vibrations of eight DOF (degrees of freedom) vehicle model using a PID controller. He applied control strategies in three different situations and examined their effects on passenger comfort and road holding [11]. Hanafi controlled of the semi-active vehicle suspension system using a PID controller in a Matlab/Simulink environment [12]. Similarly, Rao carried out semi-active suspension system control of automobiles by using a PID controller in Matlab/Simulink environment and significantly reduced the displacement and acceleration values of the vehicle body [13]. In their study, Gandhi et al. presented the performance analysis of the four DOF half-vehicle model using three different alternative controllers, except the PID controller [14].

PID type controllers can be used alone or can be used as a new controller by combining with other controllers. The most preferred of these is the Fuzzy Logic controller, where the PID coefficients can be updated continuously. Metin and Güçlü have used PID-type fuzzy controller in six DOF light rail vehicles [15]. PID controllers can be used in many areas other than trains or heavy vehicles. For example, Thenozhi et al. worked on vibration control with PID in building structures. With the Lyapunov stability theory, the PID coefficients adjusted, the controller showed stable performance even if the gain coefficients were not optimal [16]. In addition, PID controllers are highly preferred in DC motor speed control. In this regard, Adar et al. used PI and self-tuning PI controller to reach different speed values of the DC motor in a shorter time [17]. When the literature is examined in detail, there are many controllers such as LQR (Linear Quadratic Regulator) [18] [19], LQG (Linear Quadratic Gaussian) [20], $\mathrm{H}_{\infty}$ [21], and SMC 
(Sliding mode controller) [22] in addition to PID and fuzzy logic controller in active vibration control.

In this study, to control half car railway vehicle bogie excessive vibration active suspension system consisting of linear spring, damping element and the linear actuator has been used to simulate and reduce vibration of the coupled system between 4-DOF half car railway vehicle bogie and simply supported Euler-Bernoulli beam. As shown in Fig. 1, a conventional PID control algorithm and Sliding mode control (SMC), which a robust control method, have been implemented to the half car railway vehicle bogie, as shown Fig. 1, with a linear actuator. The railway car bogie's speed on the flexible structure beam is considered constant with $v=300 \mathrm{~km} / \mathrm{h}$. In addition to this, the railway car bogie's vertical responses are given when the velocity changes from $28.8 \mathrm{~km} / \mathrm{h}$ to $540 \mathrm{~km} / \mathrm{h}$ at $3.6 \mathrm{~km} / \mathrm{h}$ intervals. Then, an effective computer simulation has been programmed to analyze this coupled vibrating system in the time domain.

\section{Method}

One of the most significant sources of the vibrations that occurred on the railway vehicle bogie is vibrations generated because of the interaction between railway vehicle wheel and flexible structure. When railway vehicle moves on the structure, it becomes incline around the axis which parallel to the cross-section of the flexible structure. Actually, railway vehicle bogie and flexible structure can be considered two separate subsystems that interact with each other at the contact point between railway vehicle wheel and structure, that is why the vibrations of the flexible structure affect the railway vehicle bogie, on the other hand at the same time the vibrations of the railway vehicle bogie which moving on the structure affect to flexible beam like structures. Therefore, it is very important that the idea of reducing the vibrations occurred on the railway vehicle bogie using passive or active control technology. Because these vibrations negatively affect both passenger comfort and traveling safety of the high-speed train. For this purpose, in this study, an active vibration control algorithm has been designed to control excessive vibration due to interaction railway vehicle wheel and beam like flexible structure as shown in the Figure 2. As shown in figure, two separate active suspension systems attach to the railway vehicle bogie to control these vibrations.

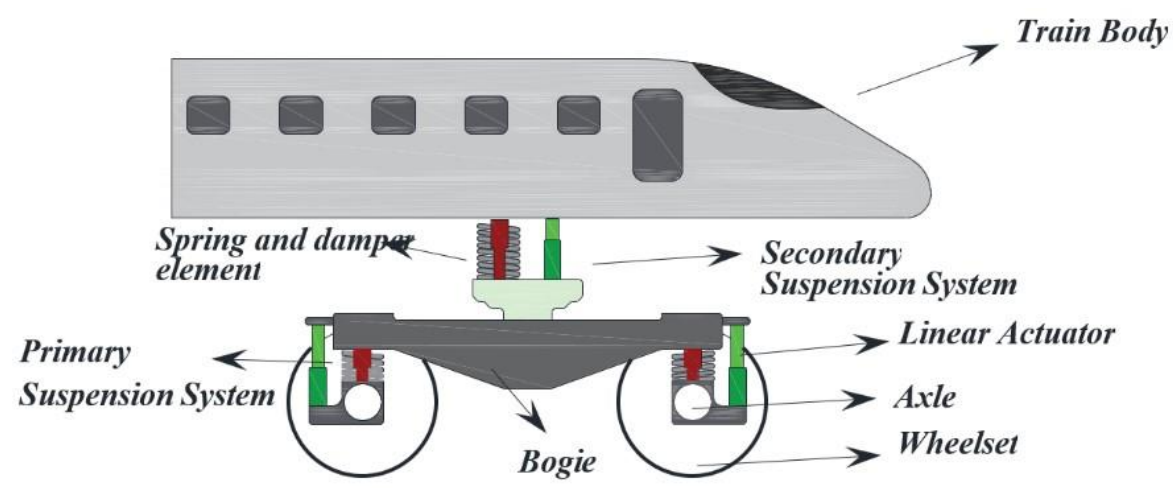

Figure 1. System configuration used in this study.

\subsection{Derivation of the equations of the motion}

In this study to mathematical model 4-DOF half car railway bogie and flexible structure, the system schema given in Figure 2 has been considered with the active suspension system attached to half car vehicle bogie. The parameters $m_{w l}$ and $m_{w 2}$ in Figure 2 represent half car railway vehicle bogie front and rear wheel mass, respectively. On the other hand, the parameters $k_{w 1}$ and $k_{w 2}$ given in Figure 2 represent half car railway vehicle front and rear suspension spring coefficients, 
respectively. The parameter mc represents half car railway vehicle bogie mass. Moreover, the parameter $I_{c}$ represents the inertial moment of the railway vehicle bogie body. Furthermore, the parameters $r_{w 1}$ and $r_{w 2}$ represent half car railway vehicle front and rear wheel vertical displacements. The parameters $r_{c}$ and $r_{\theta}$ represent half car railway vehicle body vertical displacement and angular rotation. The parameter $L$ represents the length of the bridge beam. Furthermore, the parameters $E, I, c, \mu$ represent the elasticity modulus of the bridge beam material, the cross-section inertial moment of the bridge beam, equivalent damping coefficient of the beam material, and the bridge beam mass of the unit length. The vertical displacement of the bridge $w_{b}(x, t)$ represents the deflection of any point $x$ on the beam of the bridge at time $\mathrm{t}$, relative to a reference point on the left-hand support of the beam. The symbol $v$ represents the constant velocity of the train as it moves from the left end of the beam to the right end. In the formulation for the TBI analysis, the following assumptions will be adopted.

- The flexible bridge beam is modeled as a simply supported beam based on EulerBernoulli theory considering uniform cross-section area upon bean longitudinal axis $\mathrm{x}$

- The half car railway bogie is modeled as 4-DOF lumped parameter system with active suspension and linear spring behavior.

- The velocities of railway bogie are constant, and only one railway bogie is considered moving on the Euler-Bernoulli beam

- The wheels are always in contact with the bridge, and no separation is involved during the study.

- The aerodynamic drag force is not considered in this study, and it is excluded during the study.

With these assumptions, considering given the physical model given in Figure 2, one can quickly write the kinetic and potential energies of the railway vehicle bogie and simply supported EulerBernoulli taking into account contact points between railway vehicle wheels and beam like structure. To obtain coupled equation of motion of the entire system, one can easily use the Hamilton principle given in Eq. (1):

$$
\int_{t_{i}}^{t_{i i}} \delta(T-U)+\int_{t_{i}}^{t_{i i}} \delta W_{n c} d t=0
$$

The parameters given by Eq.(1), $\delta T$ represents the total virtual kinetic energy of the entire system, the parameter $\delta U$ represents the total virtual potential energy of the railway vehicle and bridge beam coupled system. Furthermore, the parameter $\delta W_{n c}$ represents the non-conservative virtual work of the system $t=t_{i}$ and $t=t_{i i}$ time interval. So, the kinetic energy for the system shown in Figure 2 has been written as follows:

$$
T=\frac{1}{2}\left(\int_{0}^{L} \rho\left[\dot{w}^{2}(x, t)\right] d x+M_{c} \dot{r}_{1}^{2}+I_{c} \dot{r}_{2}^{2}+M_{w 1} \dot{r}_{3}^{2}+M_{w 2} \dot{r}_{4}^{2}\right),
$$

According to Eq. (2), the virtual kinetic energy of the system has been obtained as follows:

$$
\begin{aligned}
\delta T & =\int_{0}^{L} \rho \dot{w}(x, t) \frac{\partial \delta w(x, t)}{\partial t} d x+ \\
& +M_{c} \dot{r}_{1}(t) \frac{d \delta r_{1}}{d t}+I_{c} \dot{r}_{2}(t) \frac{d \delta r_{2}}{d t}+M_{w 1} \dot{r}_{3}(t) \frac{d \delta r_{3}}{d t}+M_{w 2} \dot{r}_{4}(t) \frac{d \delta r_{4}}{d t}
\end{aligned}
$$


Considering the mathematical formulation given in Eq. (3) and put into it to Eq. (1), the equation yields as follows:

$$
\int_{t_{i}}^{t_{i i}} \delta T d t=-\int_{t_{i}}^{t_{i i}}\left\{\begin{array}{l}
\int_{0}^{L} \rho \ddot{w}(x, t) d x \delta w+M_{c} \ddot{r}_{1} \delta r_{1} \\
+I_{c} \ddot{r_{2}} \delta r_{2}+M_{w 1} \ddot{r}_{3} \delta r_{3}+M_{w 2} \ddot{r}_{4} \delta r_{4}
\end{array}\right\}
$$

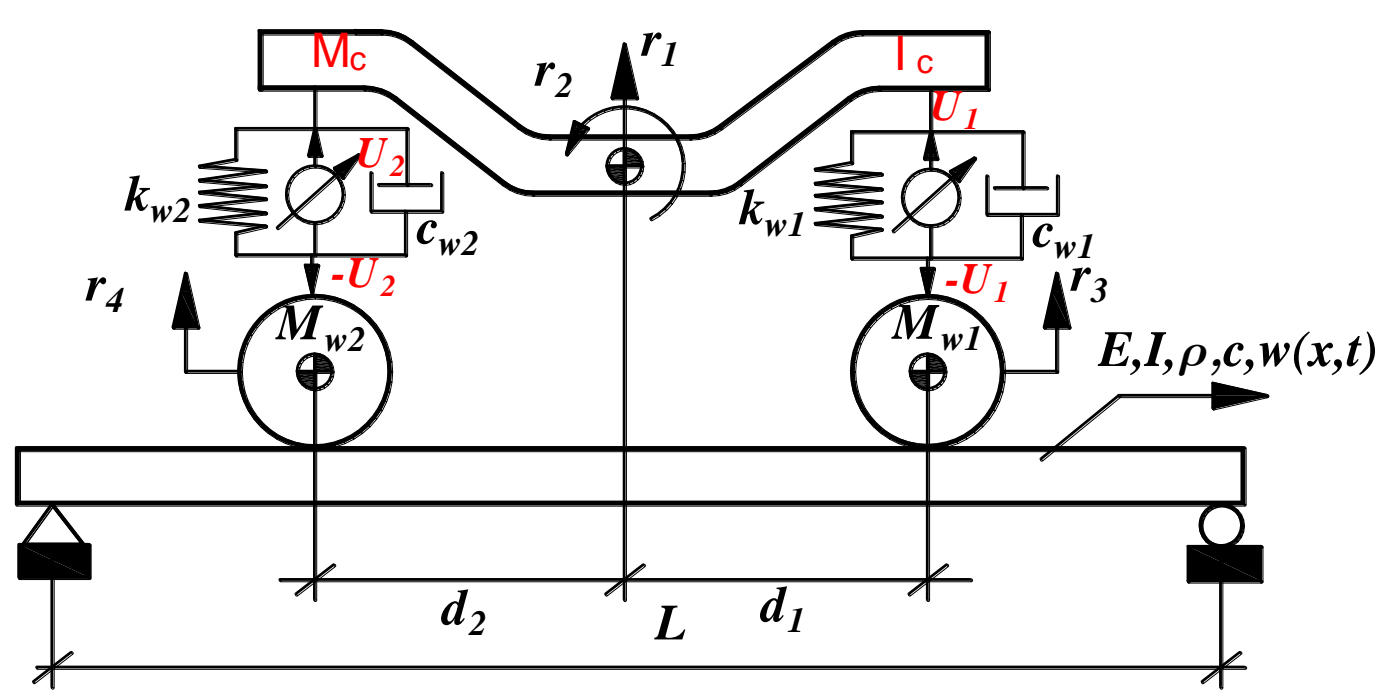

Figure 2. The physical model of the half-car railway vehicle bogie used in this study.

On the other hand, the potential energy of the half-car railway vehicle bogie and simply supported Euler-Bernoulli beam coupled system has been identified as follows:

$$
U=\frac{1}{2}\left(\begin{array}{l}
\int_{0}^{L} E I w^{\prime \prime 2}(x, t) d x+ \\
\left\{k_{w 1}\left(r_{1}+r_{2} d_{1}-r_{3}\right)^{2} H\left(x-\xi_{1}(t)\right)+k_{w 2}\left(r_{1}-r_{2} d_{2}-r_{4}\right)^{2} H\left(x-\xi_{2}(t)\right)\right\}
\end{array}\right)
$$

The parameter $E$ in Eq. (5) represents the elasticity module of the simply supported EulerBernoulli beam material, and parameter I represents the cross-section inertial moment of the uniform beam. On the other hand, the parameter $H(x)$ given in E. (5) represents the Heaviside function. The virtual potential energy has been derived taking into Eq. (5) as follows:

$$
\begin{aligned}
& \delta U=\int_{0}^{L} E I \frac{\partial w^{2}(x, t)}{\partial x^{2}} \frac{\partial \delta w(x, t)}{\partial x} d x \\
& +k_{w 1}\left(r_{1}+r_{2} d_{1}-r_{3}\right) \delta\left(r_{1}+r_{2} d_{1}-r_{3}\right) H\left(x-\xi_{1}(t)\right) \\
& +k_{w 2}\left(r_{1}-r_{2} d_{1}-r_{3}\right) \delta\left(r_{1}-r_{2} d_{1}-r_{3}\right) H\left(x-\xi_{2}(t)\right)
\end{aligned}
$$

The virtual work given by Eq. (1) of the half car railway vehicle and simply supported EulerBernoulli beam coupled vibrating system has been concluded that as shown in Eq. (7): 


$$
\begin{aligned}
& \int_{t_{i}}^{t_{i i}} \delta W_{n c} d t= \\
& \left.\frac{1}{2}\left(\int_{t_{i}}^{t_{i i}} \begin{array}{l}
-\int_{0}^{L} c \dot{w}(x, \mathrm{t}) d x \delta w \\
-c_{w 1}\left(\dot{r}_{1}+r_{2} d_{1}-\dot{r}_{3}\right) \delta_{r 1}-c_{w 1}\left(\dot{r}_{1}+r_{2} d_{1}-\dot{r}_{3}\right) \delta_{r 2}+c_{w 1}\left(\dot{r}_{1}+r_{2} d_{1}-\dot{r}_{3}\right) \delta_{r_{(}\left(\xi_{1}, t\right)} H\left(x-\xi_{1}(t)\right) \\
-c_{w 2}\left(\dot{r}_{1}-r_{2} d_{1}-\dot{r}_{4}\right) \delta_{r 1}+c_{w 1}\left(\dot{r}_{1}-r_{2} d_{1}-\dot{r}_{4}\right) \delta_{r 2}+c_{w 2}\left(\dot{r}_{1}-r_{2} d_{1}-\dot{r}_{4}\right) \delta_{r_{4}\left(\xi_{2}, t\right)} H\left(x-\xi_{2}(t)\right) \\
+\int_{0}^{L} f_{g}(x, t) d x \delta w
\end{array}\right]\right)
\end{aligned}
$$

The parameter $f_{g}(x, t)$ given in Eq.(7) represent static forces between moving half car railway vehicle wheel and simply supported Euler-Bernoulli beam, which explained with Heaviside function as follows:

$$
f_{g}(x, t)=-\left\{f_{g 1} H\left(x-\xi_{1}(t)\right)+f_{g 2} H\left(x-\xi_{2}(t)\right)\right\}
$$

Using Eqs.(3,6 and 7) given in above and put it into Eq. (1), one can easily obtain the equation of motion of the half car railway vehicle and simply supported Euler-Bernoulli beam coupled vibrations for the railway vehicle bogie body vertical displacement as follows:

$$
\begin{aligned}
\ddot{r}_{1} & =\frac{-k_{w 1}}{M_{c}}\left(r_{1}+d_{1} r_{2}-r_{3}\right)-\frac{k_{w 2}}{M_{c}}\left(r_{1}-d_{2} r_{2}-r_{4}\right)-\frac{c_{w 1}}{M_{c}}\left(\dot{r}_{1}+d_{1} \dot{r}_{2}-\dot{r}_{3}\right) \\
& -\frac{c_{w 2}}{M_{c}}\left(\dot{r}_{1}-d_{2} \dot{r}_{2}-\dot{r}_{4}\right)+\frac{U_{1}+U_{2}}{M_{c}}
\end{aligned}
$$

On the other hand, the equation of angular motion of the half car railway vehicle body has been defined as follows:

$$
\begin{aligned}
\ddot{r}_{2} & =\frac{-k_{w 1}}{I_{c}}\left(r_{1}+d_{1} r_{2}-r_{3}\right) d_{1}+\frac{k_{w 2}}{I_{c}}\left(r-d_{2} r_{2}-r_{4}\right) d_{2}-\frac{c_{w 1}}{I_{c}}\left(\dot{r}_{1}+d_{1} \dot{r}_{2}-\dot{r}_{3}\right) d_{1} \\
& +\frac{c_{w 2}}{I_{c}}\left(\dot{r}_{1}-d_{2} \dot{r}_{2}-\dot{r}_{4}\right) d_{2}+\frac{U_{1} d_{1}-U_{2} d_{2}}{I_{c}}
\end{aligned}
$$

The equation of motion of the half car railway vehicle bogie front wheel vertical displacement has been described as follows:

$$
\ddot{r}_{3}=\frac{k_{w 1}}{M_{w 1}}\left(r_{1}+d_{1} r_{2}-r_{3}\right)+\frac{c_{w 1}}{I_{c}}\left(\dot{r}_{1}+d_{1} \dot{r}_{2}-\dot{r}_{3}\right)
$$

The equation of motion of the half car railway vehicle bogie rear wheel vertical displacement can be written as follows:

$$
\ddot{r}_{4}=\frac{k_{w 2}}{M_{w 2}}\left(r_{1}-d_{2} r_{2}-r_{4}\right)+\frac{c_{w 2}}{M_{w 2}}\left(\dot{r}_{1}-d_{2} \dot{r}_{2}-\dot{r}_{4}\right)
$$

Furthermore, the equation of motion of the half car railway bogie, the simply supported EulerBernoulli beam dynamics have been described by $n$ number second differential equations in which $n$ represent mode number for the calculation of the bridge dynamics. Using these modes number one can easily be obtained bridge dynamics as shown in Eq. (13): 


$$
\begin{aligned}
& N_{i} \delta_{i j} \ddot{q}_{i}(t)+S_{i j} \delta_{i j} q_{i}(t)+c \phi_{i}^{2}(x) \dot{q}_{i}(t)-k_{w 1}\left(r_{1}+d_{1} r_{2}-\tilde{\Psi}_{1} r_{3}\right) \phi_{i}\left(\xi_{1}(t)\right) \\
& -k_{w 2}\left(r_{1}-d_{1} r_{2}-\tilde{\Psi}_{2} r_{4}\right) \phi_{i}\left(\xi_{2}(t)\right)-c_{w 1}\left(r_{1}+d_{1} r_{2}-\tilde{\Psi}_{1} r_{3}\right) \phi_{i}\left(\xi_{1}(t)\right) \\
& -c_{w 2}\left(r_{1}-d_{1} r_{2}-\tilde{\Psi}_{2} r_{4}\right) \phi_{i}\left(\xi_{2}(t)\right)=-f_{g 1} \phi\left(\xi_{1}(t)\right) \tilde{\Psi}_{1}-f_{g 2} \phi\left(\xi_{2}(t)\right) \tilde{\Psi}_{2}
\end{aligned}
$$

The parameters $q_{i}$ and $\phi_{i}$ represent generalized coordinates of the elastic deflection of the simply supported Euler-Bernoulli beam and transverse eigenfunctions of the beam, which obtain taking into boundary conditions of the simply supported Euler-Bernoulli beam. The parameter $w(x, t)$ represent deflection of the beam at any location given by parameter $x$, which is defined according to reference left side of the beam and at any time given $t$. The Galerkin approximation to define deflection of the bridge beam has been introduced as shown in Eq. (14):

$$
w(x, t)=\sum_{i=1}^{n} \phi_{i}(x) q_{i}(t)
$$

On the other hand, the orthogonality conditions of these mode shapes according to Galerkin function given by Eq. (14) have been identified as shown in Eq. (14) considering modal functions and other parameters:

$$
\int_{0}^{L} \rho \phi_{i}(x) \phi_{j}(x) d x=N_{i} \delta_{i j}, \quad \int_{0}^{L} E I \phi_{i}^{\prime \prime}(x) \phi_{j}^{\prime \prime}(x) d x=S_{i} \delta_{i j}
$$

The natural frequency of the simply supported Euler-Bernoulli beam and the corresponding critical velocity of bogie-beam system are defined as follows:

$$
\begin{gathered}
\omega_{j}^{2}=\frac{j^{4} \pi^{4} E I}{\mu L^{4}}, \\
v_{c r, j}=\frac{d w_{j}}{i}
\end{gathered}
$$

The parameter $\omega$ given in Eq. (16) represents the angular frequency of the simply supported EulerBernoulli beam with unit $(\mathrm{rad} / \mathrm{sn})$, expression $d\left(d_{1}+d_{2}=2.5 \mathrm{~m}\right)$ stands for the distance between front wheel and the rear wheel, the parameter $j$ equals to the number of the modes, the parameter $E$ represents elasticity modulus of the bridge material $\left(\mathrm{N} / \mathrm{m}^{2}\right), I$ inertial moment of the crosssection of the bridge beam $\left(\mathrm{m}^{4}\right)$, on the other hand, the parameter $\rho$ represents the mass of the unit length of the bridge beam $(\mathrm{kg} / \mathrm{m})$, the parameter $L(\mathrm{~m})$ represents the length of the bridge beam used in this study. According to this formulation, the first five mode shapes of the simply supported Euler-Bernoulli bridge beam used in this study have been shown in Figure 3. Furthermore, using half-car railway vehicle bogie and simply supported Euler-Bernoulli beam parameters given in Table 1, one can easily calculate mode frequency of the mode shapes given in Figure 3 with the formulation Eq. (16), and results belong these frequencies has been given in Table 2 with both unit's Hz and rad/s. The parameter $\widetilde{\Psi}_{1}$ and $\widetilde{\Psi}_{2}$ given in Eq. (13) represent timedependent interval of the motion which defined following two stages: 


$$
\begin{cases}0 \leq t \leq t_{1}, & \tilde{\Psi}_{1}=1, \tilde{\Psi}_{2}=0 \\ t_{1} \leq t \leq t_{2}, & \tilde{\Psi}_{1}=1, \tilde{\Psi}_{2}=1 \\ t_{2} \leq t \leq t_{3}, & \tilde{\Psi}_{1}=0, \tilde{\Psi}_{2}=1 \\ t_{3} \leq t, & \tilde{\Psi}_{1}=0, \tilde{\Psi}_{2}=0\end{cases}
$$

Table 1. The railway bogie and bridge beam parameters used in this study.

\begin{tabular}{cccc}
\hline $\begin{array}{c}\text { Bogie } \\
\text { parameters }\end{array}$ & Values & $\begin{array}{c}\text { Bridge } \\
\text { parameters }\end{array}$ & Values \\
\hline$M_{c}$ & $3,04 \mathrm{e} 3$ & $E\left(\mathrm{~N} / \mathrm{m}^{2}\right)$ & $2.07 \mathrm{e} 11$ \\
$I_{c}$ & 2080 & $I\left(\mathrm{~m}^{4}\right)$ & 0.174 \\
$M_{w 1}$ & $1,78 \mathrm{e} 3$ & $c\left(\mathrm{Ns} / \mathrm{m}^{2}\right)$ & 1750 \\
$M_{w 2}$ & $1,78 \mathrm{e} 3$ & $\rho(\mathrm{kg} / \mathrm{m})$ & 20000 \\
$k_{w 1}$ & $9 \mathrm{e} 4$ & $L(\mathrm{~m})$ & 60 \\
$k_{w 2}$ & $9 \mathrm{e} 4$ & $d_{l}$ & 1.25 \\
$c_{w 1}$ & $4,2 \mathrm{e} 3$ & $d_{2}$ & 1.25 \\
$c_{w 2}$ & $4,2 \mathrm{e} 3$ & & \\
\hline
\end{tabular}

Table 2. Mode frequency of the bridge beam used in this study.

\begin{tabular}{cccccc}
\hline Mode number & 1 & 2 & 3 & 4 & 5 \\
\hline Frequency value $(\mathrm{rad} / \mathrm{s})$ & 3,68 & 14,72 & 33,11 & 58,87 & 91,98 \\
Frequency value $(\mathrm{Hz})$ & 0,59 & 2,34 & 5,27 & 9,37 & 14,64 \\
Critical velocity of bogie- & 33,12 & 132,48 & 297,99 & 529,83 & 827,82 \\
beam system $(\mathrm{km} / \mathrm{h})$ & & & & & \\
\hline
\end{tabular}

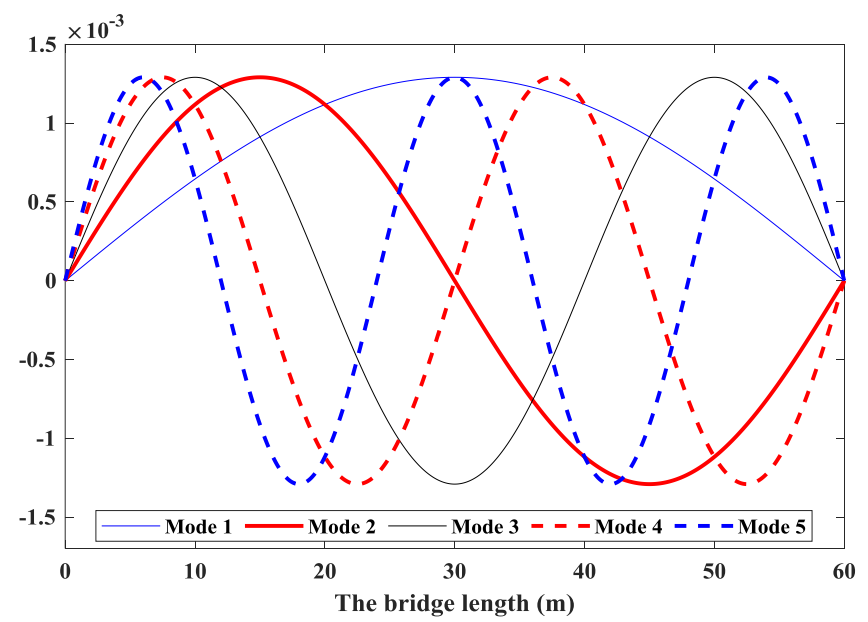

Figure 3. The mode shapes of the bridge beam used in this study.

\subsection{Solution of the equations of the motion}

In this section, the solution algorithm for the equations of motion of the half car railway bogie and simply supported Euler-Bernoulli beam has been introduced used in this study. The equation of motions of the half car railway bogie given in Eqs. (9-21) represented by four second order differential equations have been reduced to eight first order differential equations using state variables given in this study. On the other hand, simply supported Euler-Bernoulli beam equation of motion represented by second order differential equation as shown in Eq. (13). In this study, four modes have used to calculate beam transverse deflection at any of the bridge beams and at any time $t$. So, the four second order differential equations are reduced to eight first order differential equations using state variables given in this study. The number of the total first order 
differential equation has been obtained as sixteen number according to and these equations could simply be represented by in the state-space form as shown in Eq. (18):

$$
\dot{\mathbf{x}}(t)=\mathbf{A}(t) \mathbf{x}(t)+\mathbf{f}(t)
$$

The solution of the Eq. (18) has been obtained by the fourth order Runge-Kutta algorithm, and a detailed explanation about this algorithm is implemented by studies [10], [23]-[26] which previous study to investigate different type of vehicle and bridge interaction problems.

\subsection{Verification of proposed method}

In order to verify the accuracy of the proposed method in this study, a previous example in the literature was considered. In this examined verification model, all parameters were selected the same. The motion equation of the model in the literature was analyzed using the Newmark method [27]. In the example, the elasticity module of the beam was taken as $E=2.87 \mathrm{GPa}$, inertia moment of cross-sectional area was taken as $I=2.9 \mathrm{~m}^{4}$, mass of unit length of the beam was taken as $\mu=2303 \mathrm{~kg} / \mathrm{m}$, beam length was taken as $L=25 \mathrm{~m}$, sprung mass was taken as $M_{v}=5.75$ tons, wheel mass was taken as $M_{v}=0$, spring rating was accepted as $k_{v}=1595 \mathrm{kN} / \mathrm{m}$, and the system was assumed as undamped $\left(c_{v}=0\right)$.

The comparative result of the method used in this study with the example given in Figure 4 is shown in Figure 5. The verification example examined was previously conducted by Biggs [27]. The results of validation examples and the method used in this study were found to be quite similar.

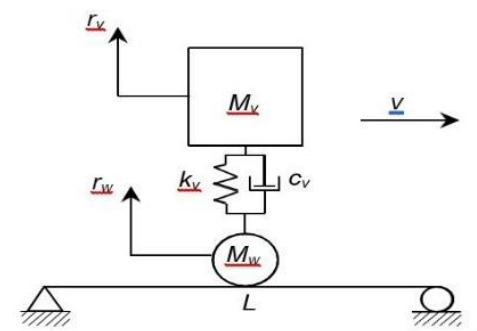

Figure 4. The verification model used in this study.

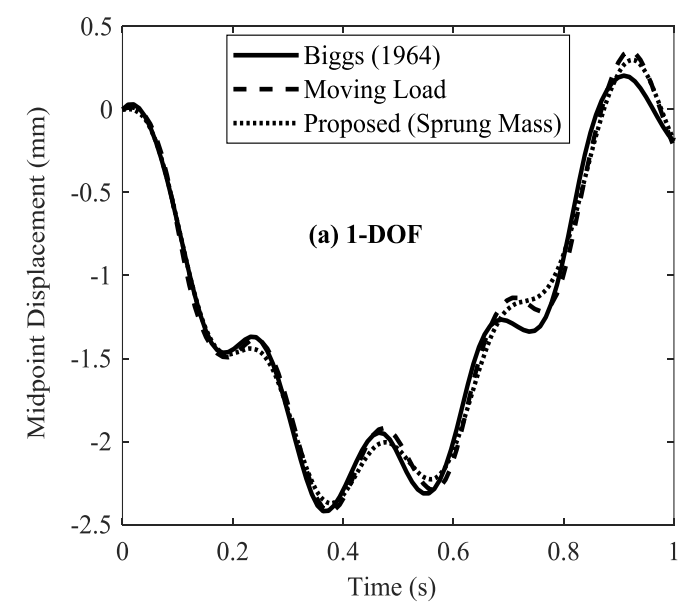

Figure 5. The comprison of model with proposed method. 


\subsection{The designing of the control schema based on PID algorithm}

In this study, as fit for the purpose of the study, a PID control algorithm has been performed to half car railway vehicle bogie's secondary suspension system given in Figure 2. The purpose of the study is decreasing of the excessive vibrations that occurred on the railway vehicle. PID controller has been used for more than $\% 90$ electrical and mechanical applications in engineering because of its simplicity and ease of application in closed-loop control applications. Therefore, it seems that it will be used for various engineering applications in the future. Figure 6 shows that conventional feedback PID control algorithm closed-loop schema. As shown in figure PID control algorithm consists of one input (reference input for the control algorithm) and one output signal of the plant system. A sensor detects this output signal, and then this signal is compared with the input reference signal using a comparison element, as shown in Figure 6. This comparison has obtained the error signal. Then, this error signal has been transferred to gain, integral and derivative elements for processing in these elements. Using these processed signals at the gain, integral and derivative element with the sum of them, the control output of the PID algorithm has been generated. This signal is transferred to the plant system (in this study the plant system is simply supported Euler-Bernoulli beam and half car railway vehicle active suspension system) for the control of the output signal generated by the system. Then, according to this control force, the system's output has been obtained

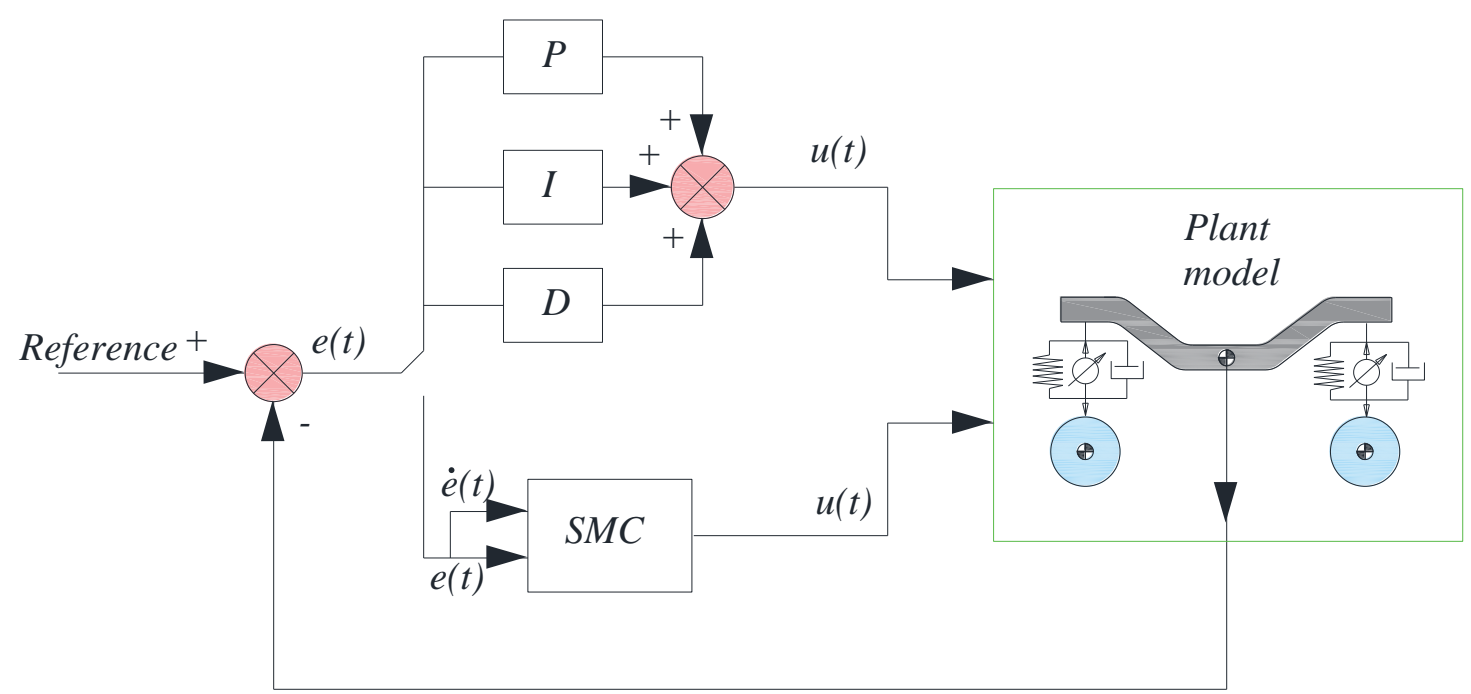

Figure 6. Conventional feedback PID and SMC control algorithms used in this study.

The control output $U_{l}(t)$ and $U_{2}(t)$ for the half car railway vehicle bogie secondary suspension's front and rear actuators has been obtained as shown in Eqs. (19a) respectively using error signal generated by PID control algorithm.

$$
U_{i}(t)=K_{p} e_{i}(t)+K_{i} \int_{0}^{t} e_{i}(t) d t+K_{d} \frac{d e_{i}(t)}{d t},(i=1,2),\left\{\begin{array}{l}
e_{1}=0-\left(r_{1}+r_{2} d_{1}\right) \\
e_{2}=0-\left(r_{1}-r_{2} d_{2}\right)
\end{array}\right\},
$$

The parameter $e(\mathrm{t})$ given in Eq. (19) represents the error signal determined by the difference between the reference signal and output signal of the plant system. On the other hand, the parameters $K_{p}, K_{i}$, and $K_{d}$ given in Eq. (19) represent respectively proportional, integral, and derivative gains of the PID controller. Figure 1 shows that system configuration of the PID controller implemented to active suspension system with the half car railway vehicle bogie. As shown figure to suppress the excessive vibrations that occurred on the half car vehicle bogie, two 
linear actuators have been placed in the railway vehicle secondary suspension system. The control signal generated by sensors attached to railway bogie frame has been transferred to PID controller then a control signal produced by the controller using Eq. (19), then, this control signal. In this considering proportional, integral, and derivative gains $K_{p}=11989, K_{i}=42264$, and $K_{d}=20765$, respectively.

\subsection{The designing of the control schema based on SMC algorithm}

In the previous section, the control algorithm of the active suspension system was made using PID. In contrast, in this section, the active suspension system based on the SMC, a robust control method, will be introduced to provide vibration control. The main purpose of SMC is to keep the variable to be controlled at the reference value, thanks to the sliding manifold obtained by using state-space forms. Then the system's state variables are first brought on the sliding manifold and kept on the reference value determined here. These statements show that the SMC structure consists of an equivalent control signal and switching control signal [28].

The total dynamic sliding mode control output is specified as follows. Here $u_{e q}$ represents the equivalent control signal, and $u_{s w}$ represents the switching control signal.

$$
u=u_{e q}+u_{s w}
$$

The error signal generated to create a sliding surface and the derivative of the error is given in the following equations. Here, $r_{d}$ represents the desired value and equals zero.

$$
\begin{array}{lll}
e_{1}=r_{d}-\left(r_{1}+r_{2} d_{1}\right) & \dot{e}_{1}=r_{d}-\left(\dot{r}_{1}+\dot{r}_{2} d_{1}\right) & \ddot{e}_{1}=r_{d}-\left(\ddot{r}_{1}+\ddot{r}_{2} d_{1}\right) \\
e_{2}=r_{d}-\left(r_{1}-r_{2} d_{2}\right) & \dot{e}_{2}=r_{d}-\left(\dot{r}_{1}-\dot{r}_{2} d_{2}\right) & \ddot{e}_{2}=r_{d}-\left(\ddot{r}_{1}-\ddot{r}_{2} d_{2}\right)
\end{array}
$$

The sliding surface is defined as follows, where $\alpha$ is the sliding surface coefficient.

$$
s_{i}=e_{i}\left(\alpha_{i}+\frac{d}{d t}\right), \quad s_{i}=\alpha e_{i}+\dot{e}_{i}, \quad \dot{s}_{i}=\alpha \dot{e}_{i}+\ddot{e}_{i} \quad i=1,2
$$

After the taking time derivative of the sliding surface using Eqs. (21-22), the control forces can be determined as follows. Here, both control signals mentioned in Eq. (20) are given together, and $k$ represents the switching signal coefficient.

$$
\begin{aligned}
& U_{1}=\left(c_{w 2} \dot{r}_{4}-c_{w 2} \dot{r}_{1}+c_{w 1} d_{1} \dot{r}_{1}+c_{w 1} d_{2} \dot{r}_{1}+c_{w 2} d_{2} \dot{r}_{1}+c_{w 2} d_{2} \dot{r}_{2}+k_{w 1} d_{1} r_{1}+k_{w 1} d_{2} r_{1}-I_{c} \alpha \dot{r}_{2}\right. \\
& +c_{w 1} d_{1}^{2} \dot{r}_{2}-c_{w 2} d_{2}^{2} \dot{r}_{2}+k_{w 1} d_{1}^{2} r_{2}+k_{w 2} d_{2}^{2} r_{2}-c_{w 1} \dot{r}_{3} d_{1}-c_{w 1} r_{3} d_{2}-c_{w 2} \dot{r}_{4} d_{2}-r_{3} k_{w 1} d_{1}-r_{3} k_{w 1} d_{2} \\
& \left.+c_{w 1} d_{1} d_{2} \dot{r}_{2}+k_{w 1} d_{1} d_{2} r_{2}-k_{w 2} d_{1} d_{2} r_{2}-M_{c} d_{2} \alpha \dot{r}_{1}\right) /\left(d_{1}+d_{2}\right)+k_{1} \operatorname{sign}\left(s_{1}\right) \\
& U_{2}=-\left(c_{w 2} \dot{r}_{4}-c_{w 2} \dot{r}_{1}-c_{w 2} d_{1} \dot{r}_{1}+c_{w 2} d_{2} \dot{r}_{2}-k_{w 2} d_{1} r_{1}-k_{w 2} d_{2} r_{1}-I_{c} \alpha \dot{r}_{2}+k_{w 2} d_{1}^{2} r_{2}+k_{w 2} d_{2}^{2} r_{2}\right. \\
& \left.+c_{w 2} \dot{r}_{4} d_{1}+r_{4} k_{w 2} d_{1}+r_{4} k_{w 2} d_{2}+c_{w 2} d_{1} d_{2} \dot{r}_{2}+M_{c} d_{1} \alpha \dot{r}_{1}\right) /\left(d_{1}+d_{2}\right)+k_{2} \operatorname{sign}\left(s_{2}\right) ;
\end{aligned}
$$

\section{Results and Discussion}

In this section, to simulate half car railway bogie and simply supported Euler-Bernoulli beam, which properties given in Table 1 previous section are used, two different cases have been considered with case 1: without control and case 2: with control given in this study. Firstly, case 1 (without control) is taken because it has only a passive suspension system, and its suspension 
properties do not adopt any change of the road condition. For this purpose, half car railway vehicle constant speed is considered $v=300 \mathrm{~km} / \mathrm{h}$ during the whole analysis. Figure 7 shows vertical responses of the half car railway bogie body considering the bogie's constant speed $v=300 \mathrm{~km} / \mathrm{h}$. The bridge span length is given by Table 1 as $60 \mathrm{~m}$. On the other hand, the bogie axle width $\left(d_{1}+d_{2}\right)$ is calculated at $2.5 \mathrm{~m}$ according to Table 1 . So, the last axle of the bogie must move 62.5 $\mathrm{m}$ from the left bridge beam completely. If considering the railway vehicle's constant speed $v=300$ $\mathrm{km} / \mathrm{h}$, the required time to lapse bridge beam of the last axle has been calculated as $0.75 \mathrm{~s}$. As shown in Figure 7, after the time $0.75 \mathrm{~s}$, the amplitude of the railway bogie vibration decreases gradually. Indeed, the time requirement of the completely damping for the vibration waves after the last axle of the railway vehicle bogie leaves the bridge beam depends on the damping ratio of the suspension system given in Figure 7. As seen in Figure 7a, the maximum vertical displacement of the railway vehicle vertical displacement has been obtained as $8.75 \mathrm{~mm}$ at time $t=0.69 \mathrm{~s}$ for passive suspension system (PSS). Whereas these value has been determined as $4.35 \mathrm{~mm}$ at time $t=0.68 \mathrm{~s}$ for active suspension system with PID (ASS with PID). And then, for active suspension system with SMC (ASS with SMC) the maximum vertical displacement of the railway vehicle vertical displacement has been obtained as $0.625 \mathrm{~mm}$ at time $t=0.66 \mathrm{~s}$. At this moment, the location of the railway vehicle bogie on the bridge is $55 \mathrm{~m}$ from the reference left side of the beam. It is seen that maximum bridge midpoint vertical deflection doesn't occur at the time of railway vehicle located precisely on the midpoint of the beam. This result is the movement frequency of the moving railway car due to its constant velocity, which is calculated by formulation $\pi v / L$ as $2.61 \mathrm{~Hz}$. According to Table 2, the beam's first and second mode frequencies have been obtained as 0.59 and 2.34, respectively. Since vehicle movement frequency is bigger than beam's first and second mode frequencies, maximum beam midpoint deflection doesn't occur at the time of railway vehicle located exactly on the midpoint of the beam.

Figure $7 \mathrm{~b}$ shows that half car railway vehicle bogie time dependent vertical acceleration considering railway vehicle bogie and bridge parameter given in Table 1. As shown in figure maximum railway vehicle bogie vertical acceleration has been obtained as $0.466 \mathrm{~m} / \mathrm{s}^{2}$ at the time, $t=0.72 \mathrm{~s}$ for PSS. Whereas other values have been determined as $0.193 \mathrm{~m} / \mathrm{s}^{2}$ at the time, $t=0.72 \mathrm{~s}$ for ASS with PID and $0.056 \mathrm{~m} / \mathrm{s}^{2}$ at the time, $t=0.72 \mathrm{~s}$ for ASS with SMC. At the moment of this time $t=0.72$, the location of the railway vehicle bogie on the flexible beam is $60 \mathrm{~m}$. That is means the half car railway vehicle completely leaves the bridge at the maximum railway bogie acceleration occurred. As it is understood that maximum railway bogie acceleration occurs further time according to maximum railway bogie vertical displacement, as shown in Figures 7a and 7b.
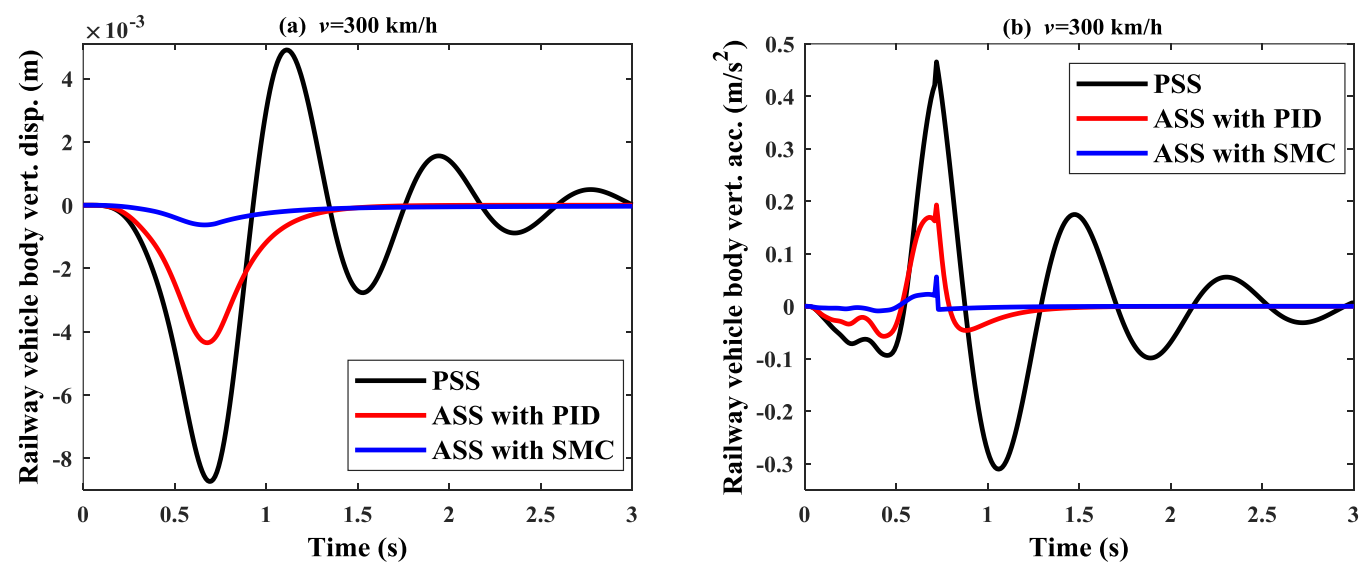

Figure 7. The effect of the active suspension systems upon railway vehicle bogie (a) vertical displacement (b) vertical acceleration. 


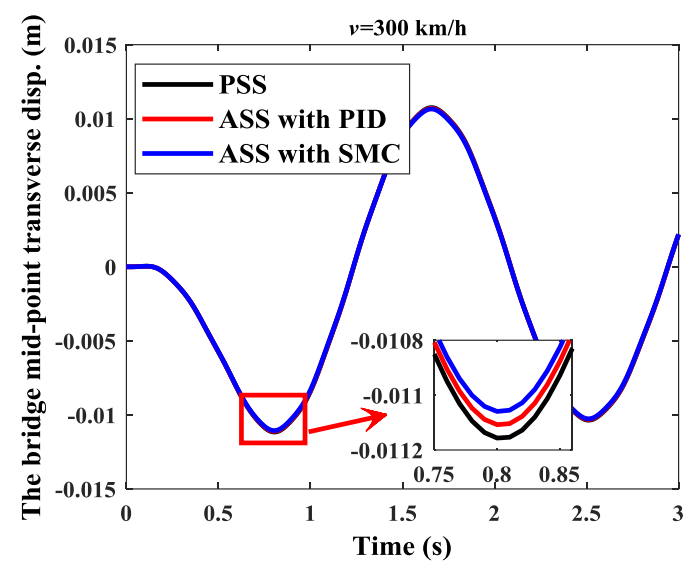

Figure 8. The effect of the active suspension system upon bridge mid-point deflection.

Figure 8 shows that simply supported Euler-Bernoulli beam time depended on mid-point transverse displacement with the railway vehicle bogie constant speed $v=300 \mathrm{~km} / \mathrm{h}$. As shown in Figure 8, the maximum mid-point transverse displacement of the bridge has been calculated as about $11.15 \mathrm{~mm}$ at time $t=0.8 \mathrm{~s}$. At this moment location of the half car railway vehicle bogie is $66.64 \mathrm{~m}$. This means that the entire axle of the railway bogie left the bridge beam. As shown in Figure 8 vibration wave of the bridge mid-point displacement is damping slightly. The reason for this that the damping ratio of the bridge beam is relatively small. If computer simulation replaced with the bridge beam, which has a highly material damping coefficient, in this case, one can easily observe that damping of the vibration wave.

Figure 8 shows that comparison of the passive suspension system and active suspension system adopted to half car railway vehicle bogie with the PID and SMC controller introduced in this study according to simply supported Euler-Bernoulli beam mid-point transverse displacement using computer simulation. According to graphs given in Figure 8, one can easily understand that active suspension systems have no significant effect in term of damping simply supported EulerBernoulli beam mid-point transverse displacement because of the maximum simply supported Euler-Bernoulli beam mid-point transverse displacement $11.15 \mathrm{~mm}$ in the case of PSS. On the other hand maximum simply supported Euler-Bernoulli beam mid-point transverse displacement $11.11 \mathrm{~mm}$ and 11.05 in the case of ASS with PID and ASS with SMC, respectively. It should be noted that the maximum vibration amplitude of the railway vehicle bogie acceleration has been reduced by about $\% 0.36$.
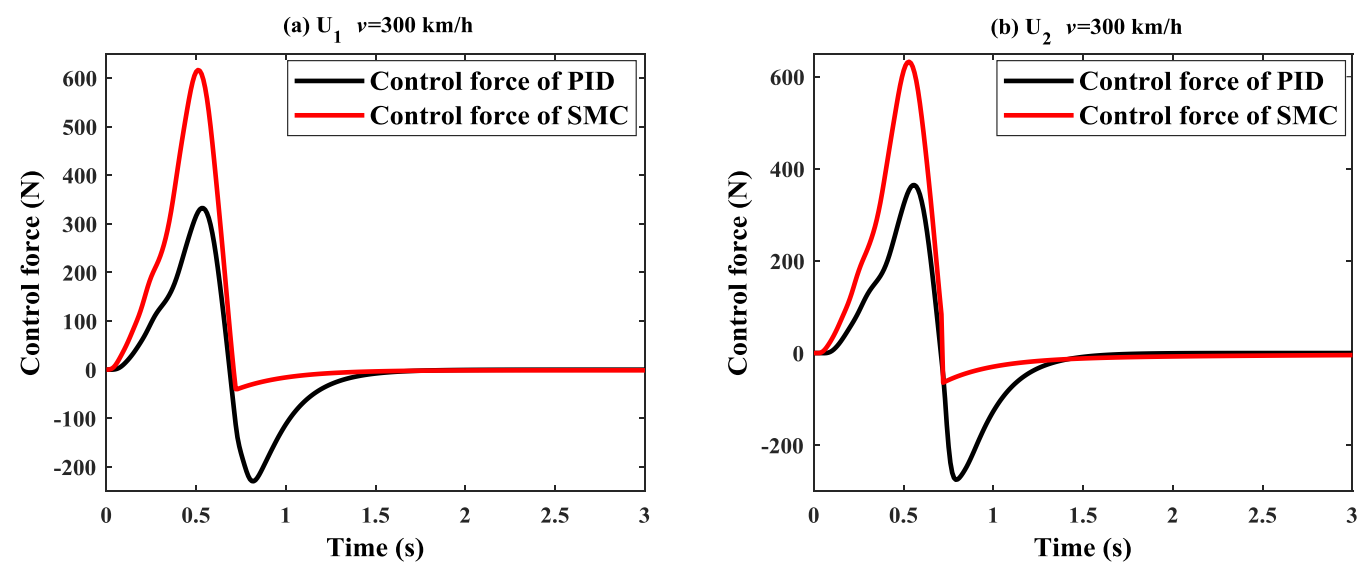

Figure 9. The generated control forces by using active suspension systems. 
In Figure 9, the control signal graph generated by two different active suspension system algorithms used in this study is given. In the railway vehicle bogie examined in the study, there are two actuators, one at the front and one at the rear, and they are indicated as $U_{l}$ and $U_{2}$ in Figure 9. When the figure is examined, it is seen that the maximum control force generated by the PID controller for the $U_{l}$ is $332 \mathrm{~N}$ in $0.53 \mathrm{sec}$, while the control force generated by the SMC is $616 \mathrm{~N}$ in $0.51 \mathrm{sec}$. A similar situation is observed in the determination of the $U_{2}$ control force. Another unique status in the graphics is that after approximately 0.7 seconds, immediately after the railway bogie leaves the bridge, the control force applied by the SMC controller decreases considerably compared to the PID. It is understood from here that the SMC control algorithm is superior to PID and is a robust control method.
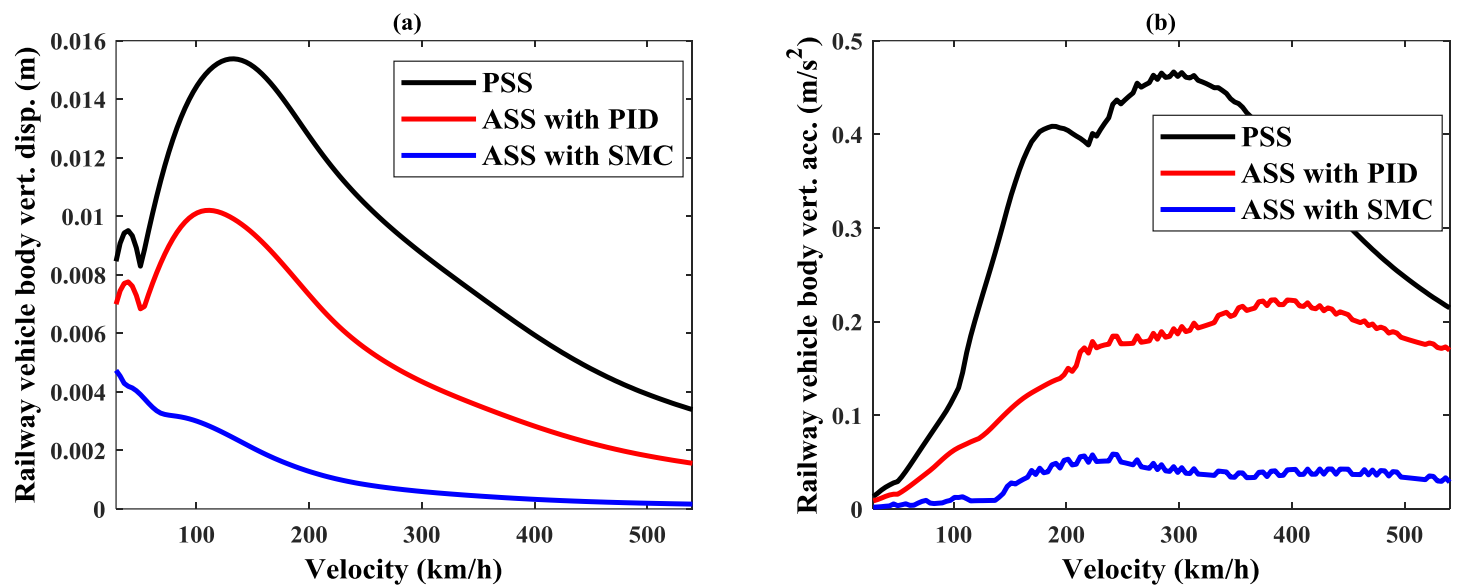

Figure 10. The effect of velocity upon railway vehicle bogie responses (a) Vehicle body vertical displacement (b) Vehicle body vertical acceleration.

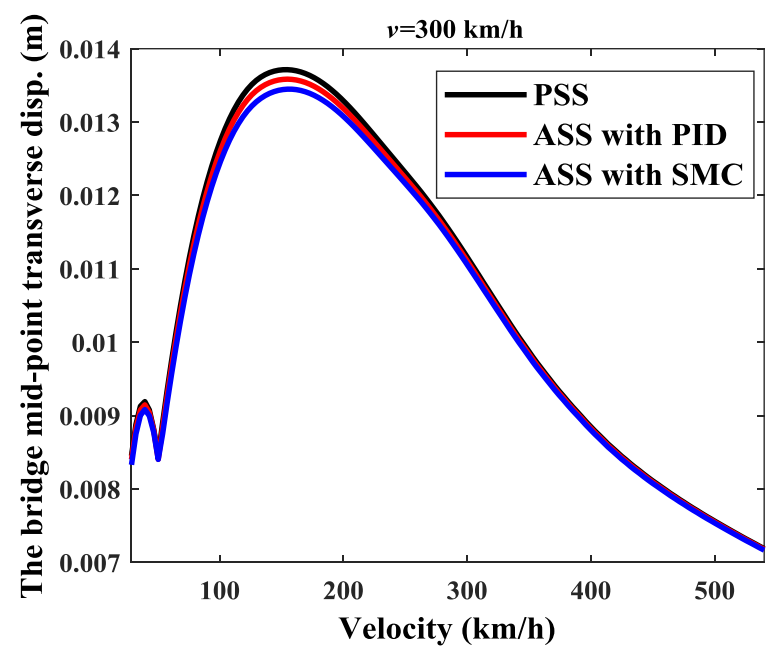

Figure 11. The effect of velocity upon the bridge mid-point transverse displacement.

Figures 10 and 11 show the maximum displacement and acceleration of the railway vehicle body and the maximum displacement of the bridge mid-point when the vehicle velocity changes from $28.8 \mathrm{~km} / \mathrm{h}$ to $540 \mathrm{~km} / \mathrm{h}$ in a $3.6 \mathrm{~km} / \mathrm{h}$ interval. Figure 10 a shows that the maximum displacement of the railway vehicle bogie is determined as $0.015 \mathrm{~m}$ when the bogie velocity is $133.2 \mathrm{~km} / \mathrm{h}$ for the PSS. In contrast the maximum displacement of the railway vehicle bogie is determined as $0.0102 \mathrm{~m}$ when the vehicle velocity is $111.4 \mathrm{~km} / \mathrm{h}$ for the ASS with PID. These values are close to the second critical velocity of the bogie-beam system calculated in the previous section. 
Similarly, in Figure 10a, if the bogie's velocity is $40 \mathrm{~km} / \mathrm{h}$, both the controlled system's maximum displacement value and the uncontrolled system are high. This velocity is also close to the first critical velocity of the bogie-beam system calculated in the previous section. According to the graph in Figure 10b, if the bogie's velocity is $295.2 \mathrm{~km} / \mathrm{h}$, the maximum railway vehicle bogie vertical acceleration value for PSS is $0.466 \mathrm{~m} / \mathrm{s}^{2}$, which is almost equal to the third critical velocity of the bogie-beam system. In Figure 11, the maximum bridge mid-point transverse displacement values occurred when the bogie velocity was $40 \mathrm{~km} / \mathrm{h}$ and $149 \mathrm{~km} / \mathrm{h}$. These velocity values are very close to the first two critical velocities of the bogie-beam system. In addition, the dynamic responses of the bridge and bogie decrease as the bogie's velocity increases.

\section{Conclusion}

In this study, to control half car railway vehicle bogie excessive vibration active suspension system consisting of linear spring, damping element and the linear actuator has been used to simulate and reduce vibration of the coupled system between 4-DOF half car railway vehicle bogie and simply supported Euler-Bernoulli beam. For the control of the active suspension system, a conventional PID control algorithm and SMC, which a robust control method, have been implemented to the linear actuator. The railway car bogie's velocity on the flexible structure beam is constant with $v=300 \mathrm{~km} / \mathrm{h}$, and variables from $28.8 \mathrm{~km} / \mathrm{h}$ to $540 \mathrm{~km} / \mathrm{h}$. Then, an influential computer simulation has been programmed to analyze this coupled vibrating system in the time domain. The root means square (RMS) values of the results obtained in the study are given in Table 3. According to obtained results in this study given in section 3, one can easily conclude the following remarks:

Table 3. RMS values for railway bogie vertical displacement and acceleration.

\begin{tabular}{ccccc}
\hline & $\begin{array}{c}\text { Bogie vertical } \\
\text { displacement }(\mathrm{m})\end{array}$ & $\begin{array}{c}\text { Relative } \\
\text { improvement }(\%)\end{array}$ & $\begin{array}{c}\text { Bogie vertical } \\
\text { acceleration }(\mathrm{m} / \mathrm{s} 2)\end{array}$ & $\begin{array}{c}\text { Relative } \\
\text { improvement }(\%)\end{array}$ \\
\hline Passive & 0.00479 & - & 0.14231 & - \\
ASS with PID & 0.00284 & 40.72 & 0.03858 & 72.89 \\
ASS with SMC & 0.00023 & 91.95 & 0.00447 & 88.41 \\
\hline
\end{tabular}

- According to graphs, one can easily understand that active suspension systems are very effective in damping railway vehicle bogie vertical displacement.

- Active suspension system with PID compared to the passive suspension system is approximately $40.72 \%$ more effective in reducing the vertical displacements of the railway vehicle bogie. While the active suspension system with SMC compared to the active suspension system with PID is approximately $91.95 \%$ more effective.

- Active suspension system with PID compared to the passive suspension system is approximately $72.89 \%$ more effective in reducing the vertical accelerations of the railway vehicle bogie, while the active suspension system with SMC compared to the active suspension system with PID is approximately $88.41 \%$ more effective.

- The idea of the placed to secondary suspension system a linear actuator has no significant effect upon Euler-Bernoulli flexible structure with the simply supported boundary conditions.

One can easily use the proposed method in this study for the different types of railway vehicle suspension system control without expensive and time-consuming experimental study with the more improved railway vehicle physical and mathematical models.

\section{References}

[1] H. Xia, N. Zhang, and W. Guo, Dynamic Interaction of Train-Bridge Systems in High-Speed Railways. 
2018.

[2] M. A. Sayeed and M. A. Shahin, "Three-dimensional numerical modelling of ballasted railway track foundations for high-speed trains with special reference to critical speed," Transp. Geotech., vol. 6, pp. 55-65, 2016, doi: 10.1016/j.trgeo.2016.01.003.

[3] M. Wang, X. Z. Li, J. Xiao, Q. Y. Zou, and H. Q. Sha, “An experimental analysis of the aerodynamic characteristics of a high-speed train on a bridge under crosswinds," J. Wind Eng. Ind. Aerodyn., vol. 177, no. March, pp. 92-100, 2018, doi: 10.1016/j.jweia.2018.03.021.

[4] W. Guo, H. Xia, and Y. L. Xu, "Dynamic response of a long span suspension bridge and running safety of a train under wind action," Front. Archit. Civ. Eng. China, vol. 1, no. 1, pp. 71-79, 2007, doi: 10.1007/s11709-007-0007-1.

[5] X. Bian, H. Jiang, C. Chang, J. Hu, and Y. Chen, "Track and ground vibrations generated by highspeed train running on ballastless railway with excitation of vertical track irregularities," Soil Dyn. Earthq. Eng., vol. 76, pp. 29-43, 2015, doi: 10.1016/j.soildyn.2015.02.009.

[6] C. Y. Xia, J. Q. Lei, N. Zhang, H. Xia, and G. De Roeck, "Dynamic analysis of a coupled high-speed train and bridge system subjected to collision load," J. Sound Vib., vol. 331, no. 10, pp. 2334-2347, 2012, doi: 10.1016/j.jsv.2011.12.024.

[7] Z. C. Zhang, J. H. Lin, Y. H. Zhang, Y. Zhao, W. P. Howson, and F. W. Williams, "Non-stationary random vibration analysis for train-bridge systems subjected to horizontal earthquakes," Eng. Struct., vol. 32, no. 11, pp. 3571-3582, 2010, doi: 10.1016/j.engstruct.2010.08.001.

[8] Z. Zhang, Y. Zhang, J. Lin, Y. Zhao, W. P. Howson, and F. W. Williams, "Random vibration of a train traversing a bridge subjected to traveling seismic waves," Eng. Struct., vol. 33, no. 12, pp. 3546-3558, 2011, doi: 10.1016/j.engstruct.2011.07.018.

[9] M. A. Koç, İ. Esen, M. Eroğlu, and Y. Çay, "A new numerical method for analysing the interaction of a bridge structure and travelling cars due to multiple high-speed trains," Int. J. Heavy Veh. Syst., vol. 28 , no. $1,2021$.

[10] M. A. Koç, "Finite Element and Numerical Vibration analysis of a Timoshenko and Euler-Bernoulli beams traversed by a moving high-speed train," J. Brazilian Soc. Mech. Sci. Eng., vol. 7, 2021, doi: 10.1007/s40430-021-02835-7.

[11]R. Güçlü, "Active control of seat vibrations of a vehicle model using various suspension alternatives," Turkish J. Eng. Environ. Sci., vol. 27, no. 6, pp. 361-373, 2003, doi: 10.3906/sag-1204-7.

[12]D. Hanafi, "PID controller design for semi-active car suspension based on model from intelligent system identification," 2010 2nd Int. Conf. Comput. Eng. Appl. ICCEA 2010, vol. 2, no. 3, pp. 60-63, 2010, doi: 10.1109/ICCEA.2010.168.

[13] K. D. Rao, Modeling, simulation and control of semi active suspension system for automobiles under MATLAB Simulink using PID controller, vol. 3, no. PART 1. IFAC, 2014.

[14]P. Gandhi, S. Adarsh, and K. I. Ramachandran, "Performance Analysis of Half Car Suspension Model with 4 DOF using PID, LQR, FUZZY and ANFIS Controllers," Procedia Comput. Sci., vol. 115, pp. 2-13, 2017, doi: 10.1016/j.procs.2017.09.070.

[15]R. G. Uc, "Vibrations control of light rail transportation vehicle via PID type fuzzy controller using parameters adaptive," Turk J Elec Eng Comp Sci, vol. 19, no. 5, pp. 807-816, 2011, doi: 10.3906/elk1001-394.

[16] S. Thenozhi and W. Yu, "Stability analysis of active vibration control of building structures using PD / PID control,” Eng. Struct., vol. 81, pp. 208-218, 2014, doi: 10.1016/j.engstruct.2014.09.042.

[17] N. G. Adar, M. Eroğlu, and R. Kozan, "PI and Self-Tuning PI Controller Design and Comparison for Speed Control of DC Motor," Int. Conf. Adv. Technol. Comput. Eng. Sci. 18), 2018.

[18] M. Nagarkar, Y. Bhalerao, G. V. Patil, and R. Z. Patil, "Multi-Objective Optimization of Nonlinear Quarter Car Suspension System - PID and LQR Control," Procedia Manuf., vol. 20, pp. 420-427, 2018, doi: 10.1016/j.promfg.2018.02.061.

[19] L. Z. Ben, F. Hasbullah, and F. W. Faris, “A comparative ride performance of passive, semi-active and active suspension systems for off-road vehicles using half car model," Int. J. Heavy Veh. Syst., vol. 21, no. 1, pp. 26-41, 2014, doi: 10.1504/IJHVS.2014.057827.

[20]Q. Zhu, J. J. Ding, and M. L. Yang, "LQG control based lateral active secondary and primary suspensions of high-speed train for ride quality and hunting stability," IET Control Theory Appl., vol. 12, no. 10, 2018, doi: 10.1049/iet-cta.2017.0529.

[21] S. Rajala, T. Roinila, M. Vilkko, O. Ajala, and J. Rauh, "Hळ Control Design of a Novel Active Quarter Car Suspension System.” 2017.

[22] Y. M. Sam, J. H. S. Osman, and M. R. A. Ghani, "A class of proportional-integral sliding mode control with application to active suspension system,” Syst. Control Lett., vol. 51, no. 3-4, pp. 217-223, 2004, 
doi: 10.1016/j.sysconle.2003.08.007.

[23] M. A. Koç and İ. Esen, "Modelling and analysis of vehicle-structure-road coupled interaction considering structural flexibility, vehicle parameters and road roughness," J. Mech. Sci. Technol., vol. 31, no. 5, 2017, doi: 10.1007/s12206-017-0403-y.

[24] M. A. Koc, M. A. Kesercipğlu, İ. Esen, and Y. Çay, "Vehicle-Bridge-Interaction Analysis Using HalfCar Model," 2016.

[25] M. A. Koc, "Dynamic Response of an Euler-Bernoulli Beam Coupled with a Tuned Mass Damper under Moving Load Excitation Authors," Sak. Univ. J. Sci. ISSN, vol. 24, no. 55932, pp. 694-702, 2020.

[26] M. A. Koç, "Dynamic Response and Fuzzy Control of Half-Car High-Speed Train and Bridge Interaction," in 8th International Symposium on Innovative Technologies in Engineering and Science 23-25, 2020, vol. 2020, no. October, pp. 519-529.

[27] J. M. Biggs, "Introduction to Structural Dynamics.” McGraw- Hill, New York, 1964.

[28] B. Özkan, "Mekatronik sistemlerde uygulanan belli başlı kontrol yöntemleri," TÜBAV Bilim Derg., pp. 302-316, 2009.

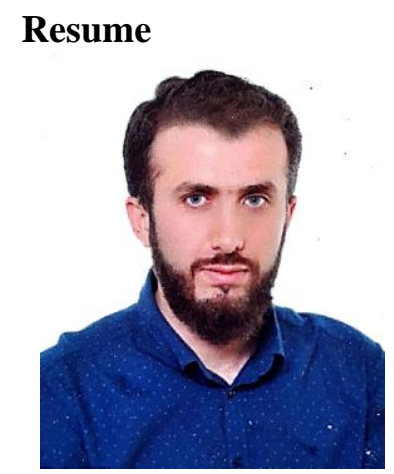

\begin{abstract}
Mehmet Akif KOÇ
Mehmet Akif Koc received M.S. degree in Mechanical Engineering from Karabuk University, Karabuk, Turkey, in 2013. He has been working as Assistant Professor in the department of Mechatronics Engineering, Sakarya Applied Sciences University, Sakarya. His current research interests include vehicle bridge interaction analysis and its control using artificial intelligence techniques.
\end{abstract}

E-mail: makoc@subu.edu.tr

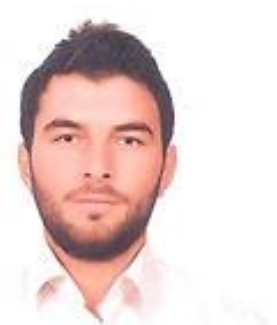

Mustafa EROĞLU

Mustafa Eroğlu is currently a Research Assistant at Department of Mechanical Engineering of Sakarya University. He earned his BS (2014), MS (2017) Degree from Karabük University, all in Mechanical Engineering. His research interests are in rail vehicle dynamics, rail wheel interaction, dynamic systems and control, robotics.

E-mail: mustafaeroglu@sakarya.edu.tr

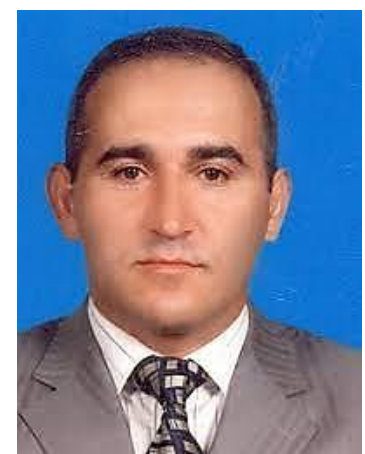

\title{
İsmail ESEN
}

Ismail Esen is currently an Associate Professor at Department of Mechanical Engineering of Karabük University. He got his BSc (1991), MSc (1994) and PhD Degrees (2009) from Istanbul Technical University, all in Mechanical Engineering. His research interests are rail vehicle dynamics, dynamic systems and control, robotics.

E-mail:iesen@karabuk.edu.tr

\section{Ethics Statement:}

Authors confirm that the article is original, there is no plagiarism issue.

All authors contributed equally. 